\title{
The Construction of Quanzhou Textile and Garment Detection Public Services Platform
}

\author{
Yinyin Wang \\ School of Business and Information Technology \\ Quanzhou Normal University \\ Quanzhou, China \\ 649047197@qq.com
}

\begin{abstract}
This paper focuses on Quanzhou textile and garment industry development requirements. Integration of talent, technology and other resources, the establishment of textile and garment inspection of public services-based, extend to the FCL, AATCC, ASTM, SCD, such as training services, laboratory construction counseling, pop or functional tag services textile and garment inspection and testing of public services. To address the majority of textile and garment enterprises are facing their own brands, quality control ability weak, the product performance instability industry common problems. Help enterprises to realize the timely, low-cost from the source control the quality of textile products, boost business "second pioneering". Promote the enterprises to enhance the capability of independent innovation. Upgrade the brand of textile products, export, driving Quanzhou textile and garment industry transformation and upgrading.
\end{abstract}

Keywords-textiles and clothing; detection; public service platform

\section{QUANZHOU TEXTILE AND GARMENT INDUSTRY DEVELOPMENT STATUS}

Quanzhou textile and garment industry are in the reform and opening up handsome. First, to promote an increase in the individual private component, vigorously the introduction of foreign companies, foreign investment, textile and garment industry has undergone tremendous changes, a new look. The Quanzhou's textile industry developed from the Shishi City and then jinjiang to the apparel market Start. Followed by the rise of the Jinjiang, Shishi dyeing and finishing industry, until to the Quanzhou the entire region chemical fiber, cotton textile, knitting, it is the expand of the dyeing and finishing clothing. After more than many years of survival of the fittest, the current has formed a chemical fiber of production capacity and textile of the spinning, cotton textile, knitting, dyeing and finishing, clothing, non--woven fabric, textile machinery. In the province showing, the textile enterprises total amount of economies of scale is large. Equipment, advanced technology, and industry, distribution tends to be intensive, large-scale, regionalization, etc. The city has nearly 20,000 textile and garment manufacturers in 2010, including about 5000 foreign-invested enterprises. As a whole textile industry output value in society has exceeded 650 billion, employing nearly 70 million people. The city's total synthetic fiber production capacity are about 50 million tons, cotton spinning spindles 30 spindles, more than 20,000 units of various types of looms. With the international advanced level of shuttleless looms, including more than 9,000 units, an annual output of shuttleless fabric billion meters, knitting circular knitting, warp knitting machine has nearly ten thousand units. Knitted fabrics reached an annual output of 40 million tons, dyeing and finishing capacity of 20 million meters of cloth 400,000,000. Jinjiang City, Quanzhou, Shishi City are the most developed areas of the textile industry which has developed rapidly in recent years in Southampton, Wai textile and garment.

The cluster development of Quanzhou textile and garment industry, regional economic formation characteristics have been formed in the country effect. The garment industry in the province has formed a chemical fiber spinning, cotton spinning, knitting, dyeing and finishing, garment, non-woven fabric, textile spinning industry production capacity and textile industrial system. The formation of the textile industry base city and the cities and towns: Jinjiang - China's textile industry base city; Shishi City - China's casual wear city; Jinjiang City - Chinese textile industry base; Shishi City Hanjiang Zhen - Chinese trousers town; town of Shishi scenery - Chinese leisure clothing city; Shenzhen and Shanghai Jinjiang Town - China underwear town; Jinjiang Ying Town - casual wear in China town. Quanzhou textile and garment industry, the formation of the textile and garment testing, training, consulting, business agents, laboratory construction and popular fabric tag window service platform has become increasingly evident demand.

\section{THE MAIN PROBLEMS OF QUANZHOU TEXTILE TESTING SERVICES}

- The textile and garment industry service organizations exists overlapping, and service organizations of the same services doesnt have the form trends of BaoTuan.

- The current area of distribution, the number and function of the textile and garment industry service organizations, are far from able to meet the needs of small and medium-sized textile and garment enterprises technical innovation.

- Lower service level of the textile and garment industry service organizations, professional degree is not 
strong, and miscellaneous services market institutions failed to form a standardized service model.

- The overall level of the fragmented nature of existing textile and garment industry service organizations is not high. It failed to form a service alliance, eventually leading to confusion in the market of services, harsh competition, from all aspects of the services market healthy and orderly development.

- Service agencies convergence phenomenon is serious. This is overly concentrated on one or a few of the same industry. The same service category subclass, counties (cities, districts) of their own development is relatively good, but the city does not have a good the collaborative trends and fusion.

\section{THE NECESSITY CONSTRUCTION OF QUANZHOU TEXTILE AND GARMENT DETECTION PUBLIC SERVICES PLATFORM}

Quanzhou textile and garment industry are the city's industrial economic pillar industries, which is one of the most competitive and the most development potential of the five traditional industries. After 30 years development, it has now built up covering cotton, chemical fiber, weaving, dyeing and finishing, clothing, accessories and more complete textile and downstream industry chain. The formation is nearly 200 billion yuan annual output. But in recent years, countries around the world prevent the destruction of the ecological environment, protecting human health and carry out a series of environmental standards, such as a carbon tax, energy tax and a series of "green barriers" that has become a major problem in the Quanzhou textile and garment export.

In the increasingly outward Chinese industry, the $t$ dependence on foreign textile industry is high. Although tariffs between the same partners are getting lower and lower, but the green barriers. Technical barriers are becoming new non-tariff barriers to trade. With the deeper concern of the people on the ecological and environmental problems, the concept of "clean production", "green products", "ecotextiles" and so on enter the international on Textiles and Clothing the field of trade. States, on textiles and apparel in the wearing is a use of the process. In the green barriers and technical barriers, the face of the original of the China's textile industry is inexpensive .If the product does not reach the related green standards, large number of international orders will work with the person or opportunity. At present, some EU buyers in order to domestic enterprises, requires reach the EU eco-textile standards $10 \%$ of the compensation payment provisions in the contract. With the upgrade of brand and the quality of domestic products, domestic also raised many safety standards such as textiles mandatory 18401 standard. As the misunderstanding of standards and operation of growing international green trade barriers, the demand for domestic producers calls for a nearby fast service and full-featured testing organizations. From the source control quality, provide more comprehensive protection.
IV. QUANZHOU TEXTILE AND GARMENT DETECTION OF PUBLIC SERVICE PLATFORM CONSTRUCTION SIGNIFICANCE AND SOCIAL ECONOMIC BENEFITS

Fujian Province, the textile industry has entered the ranks of the first group of the domestic textile industry. The size of total has been ranked fifth in the country for the development of the center. Fuzhou, Xiamen Quanzhou textile and industrial development pattern have been established from the market-oriented textile materials, polymerization, spinning, weaving, and printing and dyeing, clothing complete industrial chain development system. The comprehensive construction of the textile industry is a traditional pillar industry of the province's most dynamic and regional characteristics. The expansion of the industry and the industrial upgrading urgent, need professional export textile and garment inspection of public service platform. Detection need to be sent to Shanghai, Guangdong, and even the problem of foreign professional testing organizations to help regional textile industry. They can really control the quality of textile products from the source in a timely manner, to promote the export of textile products and foreign exchange earnings. Quanzhou textile and garment detection of public service platform for the establishment and promotion of great significance and far-reaching impact is improving the quality of Quanzhou and even the national textile to enhance the entire textile industry brand grade.

- Quanzhou textile and garment detection public service platform for the textile industry, provide third-party notarization detection, a technical advice and the standard detection. After the completion of the public service platform, it will service 500 enterprises every year. Provide enterprises with clothing and fabric testing (3000 times / year), the detection method of research and development (30 / year), the development of testing standards (30 / year), the testing standards training (100 person / times / home), the standard query (150 times / year), quality management consulting (80 / year), product quality improvement (200 / year), testing equipment patent application (10 / year), add about 150 jobs.

- $\quad$ Solve the current textile and garment enterprises in Quanzhou own brand. The ability to control quality is weak. It can help enterprises to truly control the quality of textile products from the source in a timely manner, to promote the export of textile products and foreign exchange.

- The construction of public testing service platform, Quanzhou textile and garment enterprises provide quality products inspection and testing services. Consulting testing services reduce business investment, the pressure of the lack of professional testing personnel to improve internal product quality control standards.

- Platform for the construction project fill a blank in China's southeast region of textile testing network layout to fill the Quanzhou textile industry systematic detection technology gaps.

- For the application of the platform, it will promote the send of the textile and garment enterprises in Quanzhou "second pioneering". The platform would enhance the capability of independent innovation, driven by the 
transformation and upgrading of the textile and garment industry.

\section{THE QUO OF AT HOME AND ABROAD TEXTILE AND} GARMENT DETECTION THE DEVELOPMENT OF PUBLIC SERVICE THE STATUS

In recent years, the state attaches great importance to the technology policy of the textile industry. January 1, 2005, the State General administration of Quality Supervision, inspection and Quarantine issued a "national textile products basic safety technical specifications". The implementation of the new standards will accelerate the company's survival of the fittest and textiles security ecological and environmental protection into national mandatory standards. Due to China's exports limitation and the appreciation of the renminbi. Recent years the rapid textile and garment export growth become the direct beneficiaries to Asian developing countries.

With the brand upgrade and upgrade the quality of domestic products, domestic also raised many safety standards such as textiles mandatory 18401 standard. In the face of growing international green trade barriers, domestic demand for manufacturing enterprises can upgrade the brand. A large number of export-oriented textile enterprises call for a nearby to provide fast service and fully functional testing organization. From the source control quality, provide more comprehensive protection for the product.

China Textile Industry Association testing center, is the third-party of the international standards. The commercialization of inspection agency in the field of China's textile, is the most state-of-the-art one in the current domestic.

Testing Center of China Textile Industry Association, Fujian sub-center is supported by the China Textile Information Center, led the formation by Hong Kong BOND Group Fujian, only a national third-party authority of the textile industry testing organizations. Textile detection
(Fujian) Co. Ltd as a support unit of the China Textile Industry Association Testing Center of Fujian sub-centers, the Testing Center of China Textile Industry Association in Fujian Province, is only a national textile testing agencies.

\section{QUANZHOU TEXTILE AND GARMENT CONSTRUCTION OF PUBLIC SERVICE PLATFORM DETECTED THE CORE CONTENT}

Platform around the requirements for the development of Fujian textile and garment export industry, through the integration of human resources, technology resources, initially formed mainly textile and garment inspection of public services, extension to FCL, AATCC, ASTM, SCD and other training services. Laboratory construction counseling, pop or functional tag services can assist in the preparation of corporate standards. VIP Center with the Fujian Provincial textile and garment export base Chamber of Commerce joint, need to work together enabling the unit through the development of the platform of the industry as a VIP Member (s) Available, to carry out the a series of detection preferential activities. Testing Center of China Textile Industry Association, Fujian sub-centers to grant the member units the "quality detection of sentinel units" or "strategic partner" Bronze. Specific test content is as follows:

\section{A. Textile Testing Services (Yarn, Fabric, Clothing, Accessories)}

The construction of the platform provides textile testing services as the main business content. The platform for the export base enterprise to provide the necessary testing commissioned by business, the main use of international standards and foreign standards and national standards and industry standards: AATCC, ASTM, ISO, GB, JIS, BS, EN, DIN, CAN, AS, FZ, NF, IWS, TW. The major test of the ability range is as follows:

TABLE I. THE MAIN TESTING SERVICES OF THE TEXTILES

\begin{tabular}{|c|l|l|}
\hline No. & \multicolumn{1}{|c|}{ Detection Categories } & \multicolumn{1}{c|}{ Detection Range and Capacity } \\
\hline 1 & Physical testing & $\begin{array}{l}\text { Tensile properties (strength, tear, slip, elastic), anti-pilling, abrasion resistance, bursting strength, } \\
\text { snagging. }\end{array}$ \\
\hline 2 & Color fastness testing & $\begin{array}{l}\text { Washing (soaping, Dry Cleaning), friction, illumination, water perspiration, acid-base sexual, sea } \\
\text { water, saliva, yellowed, chlorine water, chlorine bleaching and so on. }\end{array}$ \\
\hline 3 & Dimensional stability & $\begin{array}{l}\text { Washed shrinkage rate the steamed shrinkage rate to the, gas, ironing shrinkage rate, slope, } \\
\text { distorting degrees, and so on. }\end{array}$ \\
\hline 4 & Look and feel test & Crease recovery, stiffness degrees, flatness, and so on. \\
\hline 5 & Ecological indicators & PH PH value test, formaldehyde content, disabling azo and extractable heavy metals testing. \\
\hline 7 & Structural analysis & $\begin{array}{l}\text { Fiber content (qualitative, quantitative), fabric density, width, cloth weight, the thickness of, yarn } \\
\text { count, the fineness of, strong, of the Ordinance dry, hairiness, yarn faults, the shrinkage rate, the } \\
\text { oil content of, can be sewn sexual, wear-resistant, twist and so on. }\end{array}$ \\
\hline 8 & $\begin{array}{l}\text { Standard washing validation and } \\
\text { standard washing suggest that the test }\end{array}$ & $\begin{array}{l}\text { Water repellency, Chinese anti-oiliness, moisture-permeable sexual, the resistance to static water } \\
\text { pressure, an antistatic, flame-retardant sexual, UV resistant, antibacterial, Anti-Radiation, and, etc.. }\end{array}$ \\
\hline \multicolumn{2}{|c|}{\begin{tabular}{l} 
As appropriate, to ensure product washing, to maintain quality characteristics. \\
\hline
\end{tabular}}
\end{tabular}

\section{B. Training Services}

Project platform for the export of textile and garment enterprises FCL training, AATCC trains, ASTM training, SCD training and other training services.
FCL Training: The training is divided into the quality testing classes, eco-detection classes, and functional testing classes, through a variety of teaching methods, excellent teachers, with a full range of materials, issued an 
authoritative certificate, excellent corporate culture Detection talent.

AATCC Training: The training for the U.S. textile dyeing and Chemists (AATCC) authorize the China Textile Information Center in the domestic the AATCC remote standard training, participants will receive training after passing the examination have the AATCC directly issued certificate AATCC individual members.

ASTM Training: The training services include ASTM yarns, fabrics, apparel and home textiles detection methods and the United States retardant regulations and flame retardant test method ASTM care identification and use.

SCD Training: color theory and rating of the main contents of the training services, a variety of color fastness test method, dyeing theory and practice.

\section{Experimental Technology Services}

The platform for enterprises establish international textile standards laboratory to provide technical services. Recognition from the market research, laboratory testing, project planning, equipment matching, floor planning, decoration guidance, training of personnel, are the establishment of the quality management system, laboratory guidance.

\section{Tag}

The platform helps the relevant export of the "Fabrics China" textile and garment enterprises to carry out the development and achievements of new. The quality of the tag can control link to provide detection service. The comprehensive services to promote the "Fabrics China" production enterprises to enhance their competitiveness in the market, create a domestic fabric boutique brand image, establish the "Fabrics China's market position at home and abroad.

\section{E. Other Services}

The national textile fabrics Museum exclusive commissioned spinning detection (Fujian) Limited has undertaken the Fujian textile fabrics companies. All matters related to the national textile fabric shop and electronic trading platform selected for the national textile fabric shop fabric; specify spinning detection (Fujian) and so on.

\section{QUANZHOU TEXTILE AND GARMENT DETECTION OF PUBLIC SERVICE PLATFORM CONSTRUCTION TECHNOLOGY ROADMAP}

Quanzhou textile and public service platform construction is carried out on the basis of the original, including the basic needs of the textile and garment industry research. Determine the function of basic services, procurement of laboratory testing equipment, the introduction of service agencies and commissioning. This service platform will be taken to the sub-completed in the four stages of:

\section{A. The First Stage:the Service Platform For the Overall Planning and Analysis}

Main tasks: research early in the project, based on the analysis, planning and improvement of the completion of the overall project program and project feasibility studies, preparation of project-building programs.

\section{B. The Second Stage: Detection Platform Laboratory Construction and Equipment Procurement}

Main tasks: project the overall program office, according to the actual situation, and improve the work of the experimental fact, the display area, service hall environment of rehabilitation and training center. The establishment of the window service platform work for enterprise service software and hardware network cabling system.

\section{The Third Stage: the Development of Key Service Projects}

Main tasks: according to the needs of the textile and garment enterprises, have been developed. The introduction of the implementation of the various types of personalization, localization of proxy advisory services and service agencies; textile and garment detection: clothing and fabric testing, detection methods, research and development, the development of testing standards, testing standards training, standard queries, quality management consulting, product quality improvement, testing equipment Patent reporting is basically sound.

\section{Phase IV: the Perfect Platform Test Run}

Main tasks: to establish Quanzhou textile and garment industry cluster window service platform

Test run results to improve and perfect the early implementation of results; service platform in order to form a normalized, needed to run the normative management files; service platform strength publicity and promotional efforts and organizations involved in the platform services enterprises discussion summing up the work.

\section{SUMMARY}

Quanzhou textile and garment detection of public service platform construction, including textile and garment inspection of public services, FCL, AATCC, ASTM, SCD and other training services, laboratory construction counseling. Popular or functional tag service, the form of public service platform solves the majority of textile garment enterprises which are facing their own brands. The quality control ability is weak, common problems. It helps to promote the enterprises and enhance the capability of independent innovation and improve product quality, to promote the brand of textile products to upgrade product performance instability industry.

\section{ACKNOWLEDGMENT}

This research was supported by the funds from: Foundation item 1 : Construction Funds of Master 
Degree Awarded Unit of Quanzhou Normal University; Foundation item 2: Fujian university key project construction service routines "The port logistics information platform construction, Haqixi prefecture", Project Number: A103; Foundation item 3: Science Plan Project of Quanzhou, Project Number: 2012Z124, 2012Z109; Foundation item 4: Science Plan Project of Fujian "Research of cycle development mode of Fujian agricultural processing industry - Quanzhou for Example".

\section{REFERENCES}

[1] Standard upgrade help the textile and power building access V Guangwei, director of China Textile Industry Association Testing Center [J]. Textile and Apparel Weekly, 2012, No.60428: 27.

[2] Chen Qunfeng. Puning textile and garment industry development research [D], South China University of Technology, 2012.

[3] BAI Xiao. Clothing detection to be closely linked to the global the development trend [N], China quality newspaper, 2008-05-21(4). 